\title{
BISCOITOS TIPO “COOKIE” E “SNACK” ENRIQUECIDOS, RESPECTIVAMENTE COM CASEÍNA OBTIDA POR COAGULAÇÃO ENZIMÁTICA E CASEINATO DE SÓDIO ${ }^{1}$
}

\author{
C.C.H. KRÜGER ${ }^{2}$, M.C.G. COMASSETTO², L.M.B. CÂNDIDO²,
}

\author{
V.L.S. BALDINI ${ }^{3}$, M.C. SANTTUCCI ${ }^{3}$, V.C. SGARBIERI ${ }^{3, *}$
}

\begin{abstract}
RESUMO
O objetivo do presente trabalho foi a formulação e a caracterização química, nutricional e sensorial de dois tipos de biscoito, tipo "cookie" e "snack", utilizando para o enriquecimento protéico a caseína obtida por coagulação enzimática para o "cookie" e caseinato de sódio para o "snack". O biscoito tipo "cookie" apresentou teores mais elevados de umidade, proteina e fibra total que o do tipo "snack", que foi mais rico em gordura e sal. Com relação aos minerais essenciais, o biscoito tipo "cookie" apresentou-se mais rico em minerais que o "snack", exceto pelo fósforo e pelo sódio com teores mais elevados no "snack". O perfil de aminoácidos essenciais foi mais adequado no tipo "cookie" que no "snack". Conseqüentemente, os indices de valor protéico, exceto a digestibilidade verdadeira, foram superiores para os biscoitos do tipo "cookie". A aceitabilidade dos dois tipos de biscoito foi testada em atletas dos dois sexos com relação aos atributos: aceitação global, cor da superficie, odor, sabor, crocância e dureza. A aceitação dos produtos foi de $98 \%$ para os "snacks" e $81 \%$ para os "cookies". Os "cookies" tiveram o mesmo nivel de aceitação pelos homens e pelas mulheres, já os "snacks" foram mais bem aceitos pelos homens (52,7\% dos homens gostaram muito, contra apenas 37,8\% das mulheres). A análise microbiológica dos dois tipos de biscoito mostrou perfil microbiológico aceitável, com base na Portaria 451 da Secretaria de Vigilância Sanitária.

Palavras-chave: biscoito; "snacks"; "cookies"; composição; valor nutritivo.
\end{abstract}

\section{SUMMARY}

SWEET AND SALTED BISCUITS (SNACKS) ENRICHED, RESPECTIVELY, WITH ENZYME COAGULATED CASEIN AND SODIUM CASEINATE. The objective of the present work was the formulation and characterization, chemical, nutritional and sensorial, of two types of biscuits, cookie and snack, using rennet casein and sodium caseinate for cookies and snacks enrichment, respectively. The cookie type biscuit presented higher contents of moisture, protein, and total fiber than the snack type which was richer in fat and salt. As to essential minerals the cookies were richer than the snacks, except for sodium and phosphorous which were higher in the snacks. The amino acid profile was more adequate in the cookie than in the snack type. Except for true digestibility the protein value indexes were higher for the cookies. Acceptability of the two types of biscuits was tested for athlets of both sexes related to overall acceptability, surface color, odor, taste, crispness and hardness. Acceptability rated $98 \%$ for the snacks and $81 \%$ for the cookies. cookies and snacks had the same acceptability for both men and women but the snacks had higher acceptability by men $(52.7 \%)$ against $37.8 \%$ by the women. Microbiological analysis revealed an acceptable profile for both types of biscuit.

Keywords: biscuit; cookie; snack; composition; nutritive value.

\section{1 - INTRODUÇÃO}

O leite pode ser considerado o alimento mais completo da natureza e o único que satisfaz às necessidades dos recém-nascidos, de cada espécie, nos primeiros meses de vida.

O leite de várias espécies de mamíferos difere do leite humano por apresentar maior concentração de proteína total, maior concentração de caseínas e menor concentração de proteínas de soro, exceto pela $\beta$-lactoglobulina que predomina no soro de leite bovino e está praticamente ausente no soro de leite humano [4, 8].

O leite de algumas espécies animais, particularmente a bovina, contém $80 \%$ de suas proteínas como caseínas e o restante $(20 \%)$ são representadas pelas proteínas de soro, ao contrário do leite humano, no qual essa proporção se inverte, $80 \%$ das proteínas aparecem no soro e apenas $20 \%$ como caseínas [4].

1. Recebido para publicação em 24/08/2001. Aceito para publicação em 20/05/2002.

2. Universidade Federal do Paraná, Curitiba, $P R$.

3. Instituto de Tecnologia de Alimentos, Campinas-SP. Av. Brasil, 2880.

Jd. Chapadão. CEP 13001-970. Campinas, SP.

* A quem a correspondência deve ser enviada.
As caseínas podem ser obtidas a partir do leite desnatado, principalmente por dois processos [18]: precipitação no $\mathrm{pH}$ isoelétrico $\left(\mathrm{pH} 4,6,20^{\circ} \mathrm{C}\right)$; coagulação pela ação de enzimas proteolíticas (quimosina mais pepsina), como no processo industrial de obtenção de queijos.

As caseínas, no leite, são organizadas em micelas, partículas de 0,1 a $0,2 \mathrm{~mm}$ de diâmetro formadas pelas caseínas $\alpha_{\mathrm{s} 1}, \alpha_{\mathrm{S} 2}, \beta, \kappa, \gamma$, representando respectivamente $38,10,36,13$ e $3 \%$ da caseína total [10].

Além do elevado valor nutritivo, as proteínas do leite (tanto as caseínas como as proteínas do soro) conferem aos produtos formulados melhor aparência e melhores propriedades sensoriais, em virtude de suas propriedades funcionais [13], destacando-se: solubilidade e dispersibilidade, opacidade, ligação e retenção de gordura, retenção de água, emulsificação, viscosidade, estabilidade térmica, geleificação e formação de filmes, entre outras [7].

As principais aplicações das caseínas e dos caseinatos incluem produtos cárneos [12, 19], produtos lácteos [11, 19], produtos de panificação [11, 19], chocolates e confeitos, coberturas comestiveis, bebidas lácteas e achocolatadas, cremes para café, salgadinhos e "snacks" [19]. 
Nessa pesquisa utilizaram-se caseinato de sódio para elaboração de biscoitos salgados tipo "snacks" e caseína coagulada enzimaticamente e desidratada, para elaboração de biscoitos doces tipo "cookies".

\section{2 - MATERIAL E MÉTODOS}

\section{1 - Material}

$\mathrm{Na}$ elaboração dos biscoitos foram utilizados, como ingredientes, gordura vegetal, açúcar, sal de cozinha, bicarbonato de amônio, carbonato de sódio, monossódio glutamato, pimenta, água, farinha de trigo e como enriquecimento protéico usou-se caseína obtida por coagulação enzimática desidratada para os "cookies" e caseinato de sódio para os "snacks".

As proporções entre os vários ingredientes foram basicamente as mesmas utilizadas por YU \& KAUR [22].

\section{2 - Métodos}

\subsection{1 - Preparo do caseinato de sódio e do coágu- lo de caseina}

- Caseinato de sódio. Foi produzido em planta piloto no Centro de Tecnologia de Produtos de Laticínios (TECNOLAT, ITAL, Campinas). Partiu-se do leite tipo $\mathrm{B}$, desnatado e pasteurizado $\left(74^{\circ} \mathrm{C}, 20 \mathrm{seg}\right)$ e a caseína foi precipitada em seu $\mathrm{pH}$ isoelétrico $(\mathrm{pH}$ $4,6,20^{\circ} \mathrm{C}$ ) pela adição de ácido lático. Após precipitação, a caseína isoelétrica foi separada por centrifugação (Centrífuga REVAN - Ciclo CL - rotor 3000rpm) e ressuspendida em água, ajustando-se pH 7-7,5 com solução de $\mathrm{NaOH} 4 \mathrm{~N}$. Seguiu-se a desidratação em spray dryer (Niro Atomizer, Dinamarca), à temperatura de entrada de $190^{\circ} \mathrm{C}$ e de saída $95^{\circ} \mathrm{C}$.

- Caseína obtida por coagulação enzimática. Leite Tipo B desnatado e pasteurizado $\left(74^{\circ} \mathrm{C}, 20 \mathrm{seg}\right)$ foi adicionado de coalho líquido comercial, Há:La 2154CHR (30mL/100L de leite), contendo a enzima quimosina mais pepsina e solução a $50 \%$ de $\mathrm{CaCl}_{2}$ (25mL/100L de leite). A coagulação ocorreu a $34^{\circ} \mathrm{C}$ e se completou em 45-60min. O coágulo, depois de lavado com água, foi moído (moinho coloidal) e secado em spray dryer nas mesmas condições de temperatura que a caseína obtida por precipitação ácida.

\subsection{2 - Métodos analiticos}

- Composição centesimal aproximada. Os teores de umidade, cinza e gordura foram determinados, nos dois tipos de biscoitos, "cookies" e "snacks", pelos procedimentos descritos no AOAC [2] e os teores de fibra alimentar total pelo método de PROSKY et al. [14].

- Determinação de minerais. Utilizou-se espectrometria de emissão de plasma (ICP 2000 - BAIRD), versão simultânea. Após mineralização da amostra por incineração $\left(450^{\circ} \mathrm{C}\right)$, os minerais foram solubilizados em solução de ácido nítrico a 5\% e diluídos com água desionizada. Os procedimentos para o preparo das amostras e quantificação dos minerais foram os de ANGELUCCI \& MANTOVANI [1].

- Determinação de aminoácidos. O aminograma foi determinado a partir de um hidrolisado ácido $(\mathrm{HCl}$ $\left.6 \mathrm{~N}, 110^{\circ} \mathrm{C}, 22 \mathrm{~h}\right)$. Após hidrólise, o material foi filtrado em membrana de $0,22 \mu \mathrm{m}$ e transferido para balão volumétrico de $50 \mu \mathrm{L}$, completando-se o volume com água microfiltrada (MILLI Q). Alíquotas de $500 \mu \mathrm{L}$ foram evaporadas à vácuo e ressuspensas em tampão Pickering $\mathrm{pH} 2,3$. Alíquotas de $25 \mathrm{~mL}$ foram transferidas para a coluna de troca cationica de um analisador DIONEX Dx 300 para a separação, seguida de reação pós-coluna dos aminoácidos com a ninidrina. A quantificação de cada aminoácido foi feita a partir de uma mistura padrão PIERCE (Amino Acid Standard H, Lot No 20088).

\subsection{3 - Perfil microbiológico}

A análise microbiológica dos biscoitos foi realizada pelo método de VANDERVANT \& SPLIPPSPOESSER [20], constando da contagem dos seguintes microrganismos: Salmonella, coliformes totais, coliformes fecais, Staphilococcus aureus, além de bolores e leveduras. Os resultados foram comparados com os estipulados pela Portaria $n^{\circ} 451$ de 19 de setembro de 1997, da Secretaria Nacional de Vigilância Sanitária [5].

\subsection{4 - Avaliação sensorial}

Testes de aceitação dos biscoitos foram realizados com 100 atletas (55 homens e 45 mulheres), praticantes das seguintes modalidades esportivas: natação, handebol, voleibol, basquetebol, futebol de salão, com idades cuja média e mediana eram de 15 e 16 anos, respectivamente. Cada provador recebeu uma amostra de biscoito doce "cookie" e uma de biscoito salgado "snack", juntamente com fichas apropriadas para a avaliação sensorial.

As fichas continham cinco niveis de apreciação para os seguintes atributos sensoriais [6]: cor da superficie, odor, sabor, crocância, dureza, aceitação global. Os resultados foram analisados estatisticamente através do teste t de Student para dados pareados e através da distribuição de freqüências, utilizando o sistema MSTAT-C, versão 2.10 .

\subsection{5 - Digestibilidade verdadeira (Dv) e quocien- te de eficiência liquida (NPR) da proteina}

Foram utilizados três grupos de oito ratos machos da linhagem Wistar, recém-desmamados, livres de patógenos específicos (SPF), fornecidos pelo Centro de Bioterismo (CEMIB) da Universidade Estadual de Campinas.

Os animais, oito por grupo, foram mantidos individualmente em gaiolas de tela de inox, em ambiente de $21 \pm 2{ }^{\circ} \mathrm{C}$ e períodos alternados de claro-escuro de 12 horas, durante 21 dias, recebendo água e dieta ad libitum. Os primeiros sete dias foram de adaptação às 
dietas e ao ambiente de laboratório. Nos sete dias seguintes foram coletadas fezes para análise da excreção fecal. Consumo de dieta e variação de peso foram computados no início e no fim da primeira, segunda e terceira semanas de ensaio.

Dos três grupos, dois deles receberam dieta com $10 \%$ de proteína de cada um dos biscoitos e os demais ingredientes segundo o AIN (American Institute of Nutrition), AIN-93G, como descrito por REEVES et al. [16]. O terceiro grupo recebeu dieta sem proteína (aprotéica) para o cálculo da excreção de nitrogênio endógeno, usado na correção da digestibilidade aparente em digestibilidade verdadeira e cálculo do NPR [17].

\section{3 - RESULTADOS E DISCUSSÃO}

Os dados da Tabela 1 revelam pequenas diferenças na composição centesimal dos dois tipos de biscoitos elaborados. O biscoito tipo "snack" (salgado) apresentou menores teores de umidade e de fibra, porém maiores teores de gordura, proteína e cinza que os biscoitos tipo "cookie".

TABELA 1. Composição centesimal de dois tipos de biscoitos, enriquecidos com concentrados protéicos de caseína.

\begin{tabular}{ccc}
\hline $\begin{array}{c}\text { Componente } \\
(\%)\end{array}$ & \multicolumn{2}{c}{ Tipos de biscoito } \\
\cline { 2 - 3 } & "Cookie" & "Snack" \\
\hline Umidade & $8,43 \pm 0,19$ & $5,38 \pm 0,13$ \\
Gordura & $10,29 \pm 0,16$ & $14,04 \pm 0,22$ \\
Proteína & $17,59 \pm 0,16$ & $10,30 \pm 0,13$ \\
Cinza & $2,43 \pm 0,04$ & $4,09 \pm 0,10$ \\
Fibra alimentar & & 3,52 \\
(Total) & 6,09 & 52,67 \\
Carboidrato & & \\
(Diferença) & 55,17 & \\
\hline
\end{tabular}

*Resultados são médias \pm desvios padrão de três determinações, exceto fibra alimentar, cujas médias são de duas determinações.

A diferença no teor de umidade entre os dois tipos de biscoito poderá estar ligada ao maior teor de fibra no biscoito "cookie", principalmente por ser esta fibra proveniente da aveia, fibra esta com elevado poder de retenção de água. Os teores mais elevados de gordura e de proteína no biscoito "snacks" se deve à utilização desses dois componentes em mais alta proporção neste tipo de biscoito. A concentração mais elevada de cinza nos "snacks" se deve à adição de sal na sua elaboração.

Os teores de proteína nos biscoitos (Tabela 1) podem ser considerados elevados, pois a análise de um biscoito doce comercial revelou um teor de proteina de $7,31 \pm 0,05 \%$, contra $17,59 \pm 0,16 \%(10,28 \%$ mais elevada) para os "cookies". Da mesma forma, um biscoito comercial salgado, tipo "snack" apresentou 7,84 $\pm 0,17 \%$ de proteína contra 20,3\% (12,46\% mais elevada) para o "snack" da Tabela 1.
Na formulação dos "cookies" foi usada caseina obtida por coagulação enzimática com $80,8 \%$ de proteína e que apresentou PER de 3,15, enquanto que nos "snacks" utilizou-se caseinato de sódio com $76,9 \%$ de proteína e PER de 3,65 [3].

A concentração de alguns minerais essenciais, nos dois tipos de biscoito, é apresentada na Tabela 2.

Comparando a composição mineral do "cookie" e do "snack", nota-se que o "cookie" apresenta concentração mais elevada para a maioria dos elementos quantificados, exceto pelo fósforo e sódio que se apresentam mais elevados no "snack". A elevada concentração de sódio no "snack" é um reflexo da adição de $\mathrm{NaCl}$ (biscoito salgado) na formulação.

TABELA 2. Minerais essenciais em dois tipos de biscoitos enriquecidos com concentrados protéicos de caseína.

\begin{tabular}{|c|c|c|c|}
\hline \multirow{2}{*}{$\begin{array}{l}\text { Elemento mineral }^{*} \\
\qquad(\mathrm{mg} / 100 \mathrm{~g})\end{array}$} & \multicolumn{2}{|c|}{ Tipos de biscoito } & \multirow{2}{*}{$\begin{array}{l}\mathrm{RDA}^{* *} \\
\text { (mg/dia) }\end{array}$} \\
\hline & "Cookie" & "Snack" & \\
\hline Cálcio & $286,54 \pm 2,54$ & $201,40 \pm 2,70$ & 1.200 \\
\hline Potássio & $331,43 \pm 1,64$ & $210,37 \pm 3,38$ & $2.000-3.500$ \\
\hline Fósforo & $311,78 \pm 1,50$ & $372,53 \pm 4,15$ & 1.200 \\
\hline Sódio & $149,08 \pm 0,36$ & $1003,40 \pm 30,9$ & $500-2.400$ \\
\hline Magnésio & $63,49 \pm 0,89$ & $32,94 \pm 0,22$ & $350 / 280$ \\
\hline Ferro & $1,79 \pm 0,05$ & $1,36 \pm 0,01$ & $12 / 15$ \\
\hline Zinco & $1,95 \pm 0,02$ & $1,24 \pm 0,01$ & $15 / 12$ \\
\hline Manganês & $0,99 \pm 0,03$ & $0,48 \pm 0,01$ & $2,0-5,0$ \\
\hline Cobre & $0,28 \pm 0,01$ & $0,27 \pm 0,02$ & $1,5-3,0$ \\
\hline
\end{tabular}

Os valores de RDA, apresentados na Tabela 2, são para adultos jovens, masculinos e femininos, na faixa etária de 19 a 24 anos. Para o potássio e o sódio, são dadas faixas de valores, representando mínimo e máximo recomendados. Para magnésio, ferro e zinco, os valores são dados em duplicata separados por barra, sendo que o primeiro valor aplica-se ao gênero masculino e o segundo ao gênero feminino.

Comparando a riqueza mineral dos dois tipos de biscoito com a RDA, pode-se concluir que $100 \mathrm{~g}$ dos biscoitos poderiam fornecer, desde um mínimo de $10 \%$ (caso do $\mathrm{Mg}$, Fe e $\mathrm{Zn}$ ) até $100 \%$ da RDA (caso do Na) no "snack". Para os demais elementos, a contribuição de $100 \mathrm{~g}$ dos dois produtos estaria entre 10 e $100 \%$ da RDA.

Os resultados da composição de aminoácidos encontrada para os dois tipos de biscoito estão expressos, em gramas de aminoácidos por $100 \mathrm{~g}$ de biscoito e por $100 \mathrm{~g}$ de proteína, na Tabela 3. Os aminoácidos predominantes nos dois tipos de biscoito são ácido aspártico, serina, prolina, ácido glutâmico e leucina.

Quando é analisada a composição de aminoácidos na proteína (g/100g de proteína), verifica-se uma menor concentração da maioria dos aminoácidos no biscoito tipo "snack", comparado com os "cookies". Esse fato é devido à diferença de composição dos dois tipos de biscoito, bem como diferenças das variações de processamento. 
Na Tabela 4, os perfis de aminoácidos essenciais dos "cookies" e "snacks" são comparados com o perfil teórico recomendado pela FAO/WHO [9], para crianças na faixa etária de 2 a 5 anos de idade.

Observa-se que o perfil de aminoácidos essenciais do biscoito tipo "cookie" supera as recomendações da FAO/WHO [9] para todos os aminoácidos essenciais determinados, resultando em escore químico igual ou superior a 1,0. Por outro lado, a proteína do biscoito tipo "snack" apresenta-se deficiente em lisina, com apenas $80 \%$ do teor recomendado para crianças de 2 a 5 anos de idade, resultando um escore químico de aminoácidos de 0,81 tendo por base o conteúdo de lisina do padrão.

TABELA 3. Composição de aminoácidos de dois tipos de biscoito enriquecidos com concentrado protéico de caseína.

\begin{tabular}{lccccc}
\hline \multirow{2}{*}{ Aminoácidos* } & \multicolumn{2}{c}{ "Cookies" } & & \multicolumn{2}{c}{ "Snacks" } \\
\cline { 2 - 3 } \cline { 5 - 6 } & g/100g & g/100g & & g/100g & g/100g \\
& Amostra & Proteína & & Amostra & Proteína \\
\hline Ácido aspártico & 1,48 & 8,42 & & 1,26 & 6,18 \\
Treonina & 0,81 & 4,59 & & 0,74 & 3,64 \\
Serina & 1,07 & 6,07 & & 1,07 & 5,25 \\
Ácido glutâmico & 4,44 & 25,25 & & 4,92 & 24,22 \\
Prolina & 1,67 & 9,49 & & 1,99 & 9,78 \\
Glicina & 0,54 & 3,06 & & 0,45 & 2,20 \\
Alanina & 0,72 & 4,08 & & 0,60 & 2,96 \\
Cistina & 0,25 & 1,43 & & 0,20 & 2,96 \\
Valina & 0,92 & 5,20 & & 1,01 & 4,95 \\
Metionina & 0,40 & 2,30 & & 0,51 & 2,50 \\
Isoleucina & 0,75 & 4,28 & & 0,79 & 3,90 \\
Leucina & 1,64 & 9,33 & & 1,65 & 8,13 \\
Tirosina & 0,64 & 3,62 & & 0,74 & 3,64 \\
Fenilalanina & 0,89 & 5,05 & & 0,89 & 4,40 \\
Lisina & 1,00 & 5,66 & 0,95 & 4,66 \\
Histidina & 0,40 & 2,30 & & 0,40 & 1,99 \\
Arginina & 0,78 & 4,44 & & 0,55 & 2,71 \\
\hline
\end{tabular}

* Triptofano é destruído durante hidrólise ácida da proteina.

TABELA 4. Perfis de aminoácidos essenciais e escores químicos de dois tipos de biscoito enriquecidos com concentrados protéicos de caseína (Referência ao padrão FAO/WHO [9]).

\begin{tabular}{lccc}
\hline \multicolumn{1}{c}{$\begin{array}{c}\text { Aminoácido } \\
\text { essencial** } \\
\text { (g/100g proteína) }\end{array}$} & \multicolumn{2}{c}{ Tipos de biscoito } & FAO / WHO ${ }^{1}$ \\
\cline { 2 - 3 } & "Cookie" & "Snack" & \\
\hline Treonina & 4,6 & 3,6 & 3,4 \\
Cistina + metionina & 3,7 & 3,5 & 2,5 \\
Isoleucina & 4,3 & 3,9 & 2,8 \\
Leucina & 9,3 & 8,1 & 6,6 \\
Valina & 5,2 & 5,0 & 3,5 \\
Tirosina + & 8,6 & 8,0 & 6,3 \\
Fenilalanina & & & \\
Lisina & 5,7 & $4,7^{*}$ & 5,8 \\
Histidina & 2,3 & 2,0 & 1,9 \\
\hline Escore químico & 1,0 & 0,81 &
\end{tabular}

$$
\text { (E.Q.) }
$$

${ }^{1}$ Recomendado para crianças na faixa etária de 2 a 5 anos.

$80 \%$ da recomendação

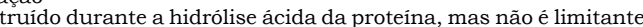
em produtos protéicos à base de caseína.
Na Tabela 5 são apresentados os valores de NPR, Dv e PDCAAS para os dois tipos de biscoito elaborados. O biscoito tipo "cookie", apesar de ter apresentado menor digestibilidade de proteína que o tipo "snack", apresentou NPR e PDCAAS mais elevados, indicando melhor valor nutritivo da proteína no biscoito "cookie" que no "snack".

A menor digestibilidade da proteína no biscoito "cookie" provavelmente se deve ao maior teor de fibra em sua formulação.

Uma dieta com $10 \%$ de caseína comercial foi usada como referência, tendo apresentado um valor NPR de 4,33 , que não diferiu do biscoito "cookie", porém foi superior ao do "snack". A digestibilidade verdadeira da caseína na dieta referência foi $96,5 \%$, superior ao valor encontrado nos dois tipos de biscoito.

TABELA 5. Quociente de eficiência líquida da proteína (NPR), digestibilidade verdadeira da proteína (Dv) e escore químico corrigido pela digestibilidade verdadeira da proteína (PDCAAS) de dois tipos de biscoito enriquecidos com concentrados protéicos de caseína.

\begin{tabular}{ccc}
\hline Índices & \multicolumn{2}{c}{ Tipos de biscoito } \\
\cline { 2 - 3 } determinados & "Cookie" & "Snack" \\
\hline${ }^{1} \mathrm{NPR}$ & $4,28 \pm 0,30^{\mathrm{a}}$ & $3,85 \pm 0,26^{\mathrm{b}}$ \\
${ }^{2} \mathrm{Dv}(\%)$ & $92,2 \pm 1,0^{\mathrm{b}}$ & $94,2 \pm 2,0^{\mathrm{a}}$ \\
& & \\
${ }^{3} \mathrm{PDCAAS}(\%)$ & 92,2 & 76,3
\end{tabular}

${ }^{1} \mathrm{NPR}=$ ganho de peso grupo em dieta com $10 \%$ proteína + perda de peso grupo em dieta aprotéica/proteina ingerida grupo em dieta $10 \%$ proteina $\mathrm{Dv}(\%)=$ nitrogenio absorvido/nitrogênio ingerido (corrigido pela excreção de nitrogênio da dieta aprotéica) x 100
${ }^{2} \mathrm{PDCAAS}(\%)=$ Dv $(\%)$ x EQ (Tabela 4$)$

A Tabela 6 resume a pontuação dos atributos sensoriais atribuída pelos atletas que avaliaram os produtos.

A maior pontuação para aceitação global esteve entre gostei e gostei muito, tendo somando 81 pontos ou $81 \%$ de aceitação para os "cookies" e $98 \%$ para os "snacks", portanto, uma aceitação global maior para os "snacks" que para os "cookies".

Os seguintes atributos individuais foram atribuídos respectivamente para "cookies" e "snacks": cor da superficie, 79 e $86 \%$; odor, 73 e $63 \%$; sabor doce/salgado, 60 e $85 \%$; crocância, 38 e 63\%; dureza, 48 e $92 \%$ e foram classificados pelos atletas como bom. A pontuação para sabor bom e muito agradável atingiu 76 e $77 \%$ para "cookies" e "snacks", respectivamente.

A aceitação dos "cookies" foi a mesma tanto para homens quanto para mulheres. Os "snacks" foram melhor aceitos pelos homens, 52,72\% deles responderam que gostaram muito, enquanto que para as mulheres este valor foi de $37,77 \%$.

Os atletas consideraram o sabor dos "snacks" melhor que o dos "cookies"; $40 \%$ responderam que os 
"snacks" tinham sabor muito agradável em contrapartida a $22 \%$ para os "cookies".

TABELA 6. Perfil de aceitabilidade de dois tipos de biscoito enriquecidos com concentrados protéicos de caseína.

\begin{tabular}{|c|c|c|}
\hline \multirow{2}{*}{$\begin{array}{l}\text { Atributo sensorial } \\
\text { (\% de aceitação) }\end{array}$} & \multicolumn{2}{|c|}{ Tipos de biscoito } \\
\hline & "Cookie" & "Snack" \\
\hline \multicolumn{3}{|l|}{ Aceitação global } \\
\hline Gostei muito & 12 & 46 \\
\hline Gostei & 69 & 52 \\
\hline \multicolumn{3}{|l|}{ Cor da superfície } \\
\hline Boa & 79 & 88 \\
\hline \multicolumn{3}{|l|}{ Odor dos biscoitos } \\
\hline Bom & 72 & 63 \\
\hline \multicolumn{3}{|l|}{ Sabor dos biscoitos } \\
\hline Muito agradável & 22 & 40 \\
\hline Bom & 51 & 36 \\
\hline \multicolumn{3}{|l|}{ Sabor doce/salgado } \\
\hline Bom & 59 & 86 \\
\hline \multicolumn{3}{|l|}{ Crocância } \\
\hline Boa & 38 & 63 \\
\hline \multicolumn{3}{|l|}{ Dureza } \\
\hline Boa & 49 & 91 \\
\hline
\end{tabular}

A análise dos dados através do teste de Student para dados pareados, revelou diferença estatisticamente significativa $(\mathrm{p} \leq 0,05)$ para aceitação global, cor da superficie, sabor, crocância e dureza entre os dois tipos de biscoitos.

Segundo VITTI [21], as proteínas de leite são excelentes ingredientes para elaboração de produtos de panificação, podendo melhorar o aroma, o sabor, a textura, a vidade-prateleira e o valor nutritivo desses produtos.

Em virtude da boa aceitação e do elevado valor protéico, esses produtos seriam indicados particularmente para esportistas e também para crianças.

A Tabela 7 mostra o perfil microbiológico dos biscoitos elaborados.

TABELA 7. Perfil microbiológico de dois tipos de biscoito enriquecidos com concentrado protéico de caseína.

\begin{tabular}{lcc}
\hline \multirow{2}{*}{ Contagem de microorganismo } & \multicolumn{2}{c}{ Tipos de biscoito } \\
\cline { 2 - 3 } & "Cookie" & "Snack \\
\cline { 2 - 3 } Coliformes a $45^{\circ} \mathrm{C}(\mathrm{NMP} / \mathrm{g}){ }^{1}$ & $<1 \times 10$ & $<1 \times 1 \mathrm{c}$ \\
Salmonella (em $25 \mathrm{~g})$ & Ausente & Ausentt \\
Staphilococcus (coagulase + ) & Ausente & Ausentt \\
\hline
\end{tabular}

${ }^{1}$ Número mais provável/grama

De acordo com a Portaria ${ }^{\circ} 451$ [5] da Secretaria Nacional de Vigilância Sanitária, pães e produtos de panificação devem apresentar ausência de Salmonella em $25 \mathrm{~g}$ do produto.
Os dados da Tabela 7 revelam ausência de Salmonella e de Staphilococcus (coagulase +). A contagem de coliformes totais ficou muito abaixo dos limites estabelecidos pela Portaria 451. Essa portaria não estabelece os valores máximos para coliformes totais em biscoitos.

\section{4 - CONCLUSÕES}

De um modo geral, tanto os "cookies" quanto os "snacks" elaborados podem ser considerados microbiologicamente adequados para o consumo.

\section{5 - REFERÊNCIAS}

[1] ANGELUCCI, E., MANTOVANI, D.M.B. Minerais em alimentos. Instituto de Tecnologia de Alimentos, Campinas, 1986, 131p.

[2] AOAC - Association of Official Analytical Chemists, Official Methods of Analysis, $15^{\text {th }}$ edition, W. Horwitz (ed.), 1990, v. 2, p. 1167-1174.

[3] BORGES, P.Z.; SGARBIERI, V.C.; JACOBUCCI, H.B.; DIAS, N.F.G. Avaliação nutricional de concentrado protéico de soro de leite, caseinato de sódio e coágulo de caseína, comparados à caseína comercial. Anais do III Simpósio Latino-Americano de Ciência de Alimentos, Campinas, 16 a 19 de novembro, 1999. Resumo 113/114.

[4] BOUNOUS, G.; KONGSHAVN, P.A.L.; TAVEROFF, A.; GOLD, P. Evolution traits in human milk proteins. Medical Hypothesis, 27, 133-140, 1988.

[5] BRASIL. Ministério da Saúde. Secretaria de Vigilância Sanitária, Portaria ${ }^{\circ} 451$ de 19 de setembro de 1997. Diário Oficial da República Federativa do Brasil, Brasília, 16 de janeiro, 1998.

[6] CÂNDIDO, L.M.B. Obtenção de concentrados e hidrolisados protéicos de Tilápia do Nilo (Oreochromus niloticus): composição, propriedades nutritivas e funcionais. Tese apresentada à Faculdade de Engenharia de Alimentos da Universidade Estadual de Campinas, para obtenção do Título de Doutor em Ciência de Alimentos, 1998, 207p.

[7] CHEN, H. Functional properties and applications of edible films made of milk proteins. Journal of Dairy Science, v. 78, n. 11, p. 2563-2583, 1995.

[8] DE WIT, J.N. Nutritional and functional characteristics of whey proteins in food products. Journal of Dairy Science, v.81, n.3, p. 597-608, 1998.

[9] FAO/WHO - Food and Agricultural Organization / World Health Organization. Report of a Joint FAO/WHO Expert Consultation on Protein Quality Evaluation, Maryland, USA, 1990.

[10] FOX, P.F.; MULVIHILL, D.M. Milk proteins: molecular, colloidal and functional properties. Journal of Dairy Research, Shinfield, v. 49, n. 4, p. 679-693, 1982.

[11] GIESE, J. Proteins as ingredients: types, functions, applications. Food Technology, v. 48, n. 10, p. 50-60, 1994.

[12] KINSELLA, J.E. Milk proteins: physicochemical and functional properties. RCR Review in Food Science and Nutrition, v. 21, n. 3, p. 197-262, 1984.

[13] LAWSON, MA. Milk proteins as food ingredients. Food Technology, v.48, n.10, p. 101, 1994.

[14] PROSKY, L.; A.S.P.; N.G.; FURDA, I.; DEVRIES, J.W.; SCHWEIZER, T.F.; HARLAND, B.F. Determination of total dietary fiber in foods, food products and total diets: interlaboratorial study. Journal of Association of 
Official Analytical Chemists, v. 67, n. 6, p. 1044-1052, 1984.

[15] RDA - Recommended Dietary Allowances, 10 th Edition, National Research Council, National Academy Press, 1989, Washington, DC, 284p.

[16] REEVES, P.G.; NIELSEN, F.H.; FAHEY JR., G.C. AIN-93 purified diets for laboratory rodents: report of the American Institute of Nutrition ad hoc Writing Committee on the reformulation of the AIN-76 rodent diet. The Journal of Nutrition, Bethesda, v. 123, n. 2, p. 467472, 1993.

[17] SGARBIERI, V.C. Alimentação e Nutrição: fator de saúde e desenvolvimento. Editora ALMED, São Paulo, 1987, pp.243-261.

[18] SGARBIERI, V.C. Proteinas em alimentos protéicos: propriedades, degradações, modificações. Editora Varela, 1996, São Paulo, p. 259-335, 357p.
[19] SOUTHWARD, C.R. Use of casein and caseinates. In: Developments in Dairy Chemistry-4. Fox, PF (ed.), Elsevier Applied Science Publishers, New York, 1989, $38 \mathrm{p}$.

[20] VANDERVANT, C.; SPLIPPSPOESSER, D.F. Compedium of Methods for Microbiological Examination of Foods, $3^{\text {rd }}$ edition, American Public Health Association, 1992.

[21] VITTI, P. Soro de leite e seu uso em panificação. Boletim do ITAL, Campinas, v. 18, n. 2, p. 155-166, 1981.

[22] YU S.Y.; KAUR, R. Development of fish biscuits from Round Scad (Decapterus russelli Rupp). Tropical Science, v.32, n.3, p. 289-294, 1992.

\section{6 - AGRADECIMENTOS}

Agradecimentos. Os autores agradecem a ajuda financeira da FAPESP para a execução desta pesquisa. 